\title{
Comparison of Permanent Mandibular Molar Crown Dimensions between Mongolians and Caucasians
}

\author{
Yuh Hasegawa ${ }^{1,2 *}$, James R. Rogers ${ }^{2}$, Ikuo Kageyama ${ }^{1}$, Sen Nakahara ${ }^{3}$, Grant C. Townsend ${ }^{2}$ \\ ${ }^{1}$ School of Life Dentistry at Niigata, The Nippon Dental University, Niigata, Japan \\ ${ }^{2}$ School of Dentistry, The University of Adelaide, Adelaide, South Australia, Australia \\ ${ }^{3}$ School of Life Dentistry at Tokyo, The Nippon Dental University, Tokyo, Japan
}

ABSTRACT The aims of this study were to compare crown dimensions of mandibular first molars (M1) and second molars (M2) between Mongolians (belonging to the Khalkha-Mogol grouping) and Caucasians (Northern European ancestry) and to attempt to explain any observed differences in phylogenetic and ontogenetic terms. Materials in this study comprised dental casts of 48 Mongolian female subjects with a mean age of 20.5 years and 50 Caucasian female subjects with a mean age of 21.5 years. For M1, the buccolingual diameters of both mesial and distal crown components in Mongolians were significantly larger than in Caucasians. For M2, the mesiodistal and buccolingual diameters of the

Mongolia is a sparsely populated, landlocked country between Russia and the People's Republic of China. The capital city is Ulaanbaatar and the population is around 2.4 million. The Mongol confederation was established by Ghengis Khan in 1206 but after the fall of the Great Mongolian Empire, during the Qing Dynasty of China, tribal alignments became more rigid as they were incorporated into a more centralized administrative system imposed by the Chinese. Ethnohistorically, the Mongolian population can be divided into four clusters comprising Khalkha-Mongols, Western or Oirat Mongols, Turkic speakers, and a Northeastern cluster. The Khalkha-Mongols make up the majority of modern Mongolians and they are dispersed throughout the country (Chimge and Batsuuri, 1999).

It is well established that there are two patterns of dental variation in Mongoloid populations. One is the Sundadont pattern, typical of South-East Asia, and the other is the Sinodont pattern, typical of North-East Asia. Sundadonts whose teeth are relatively simple are thought to have retained dental features similar to those evident in late Pleistocene populations. Sinodonts were first recognized in a large skeletal series originating in Northern China and are hypothesized to have evolved from the Sundadont condition, developing a relatively more specialized and complex dental pattern. Turner distal crown components in the Mongolian sample were significantly larger and the mesiodistal and buccolingual diameters of mesial components were significantly smaller compared with those of Caucasians. Common environmental effects, possibly related to the prenatal environment, as well as genetic influences, may be contributing to the differences in buccolingual dimensions of M1 between Mongolians and Caucasians. Given that the M2 develops later and over a longer period of time than the M1, it is reasonable to assume that this tooth may be subject to greater environmental pressures than applied to the M1. Dental Anthropology 2007;20:1-6.

(1990) observed this dental pattern in populations of Northern China, Mongolia, and Southern Siberia. Even though frequencies of occurrence and degrees of expression of nonmetric morphological crown features have been described in many Asian populations, including Mongolians (Scott and Turner, 1998; Turner, 1990; Manabe et al., 2003), there have been only a few studies describing mesiodistal and buccolingual crown diameters in Mongolians (Matsumura, 1995; Matsumura and Hudson, 2005; Hanihara, 2005). Recently, more emphasis has been placed on describing how the various components of the dental crown contribute to overall crown size, with studies focussing on intracoronal components rather than traditional mesiodistal and buccolingual crown diameters. However, as far as we are aware, no such study has been carried out in Mongolians.

Therefore, the aim of this study was to compare not only overall crown size but also the sizes of various crown components (i.e., talonid and trigonid) of mandibular

*Correspondence to: Yuh Hasegawa, School of Life Dentistry at Niigata, The Nippon Dental University, 1-8, Hamaura-chou, Chuuou-ku, Niigata-city, Niigata, Japan 951-8580

E-mail: haseyu@ngt.ndu.ac.jp 
first and second molars between a sample of modern young female adult Mongolians and a sample of female Caucasians of similar ages, and to attempt to explain any observed differences in phylogenetic and ontogenetic terms. The study forms part of a larger investigation of the Mongolian dentition being undertaken by researchers from the Health Science University of Mongolia, Mongolia, and the Nippon Dental University School of Life Dentistry, Japan.

\section{MATERIALS AND METHODS}

Materials in this study comprised dental casts of 48 Mongolian female subjects and 50 Caucasian female subjects. The Mongolian dental casts were produced from impressions collected by a survey team from the Nippon Dental University School of Life Dentistry, Japan. This material is stored at the School of Dentistry, Health Science University of Mongolia, Ulaanbaatar, Mongolia. The ages of the Mongolian subjects ranged between 18.4 and 25.0 years, with a mean age of 20.5 years. Mongolian dental casts were collected from students attending colleges and universities in Ulaanbaatar, who were born in Ulaanbaatar or its suburbs and who belonged to the Khalkha-Mogol grouping. The Caucasian dental casts are stored in the School of Dentistry, The University of Adelaide, and were obtained from dental students between 20.8 and 24.5 years, with a mean age of 21.5 years. For the Caucasian group, only those students with Northern European ancestry were chosen.

Dental casts were used only if mandibular first and second molars (M1 and M2) had no caries, no dental treatment, no anomaly of crown morphology, and only if the cusp tips, central pits and occlusal grooves were not noticeably affected by tooth wear. According to ethical standards, it was necessary for Mongolian students to be told the purpose of the study and agreements were obtained from them before impressions for dental casts were taken. Casts of the dentitions of the Adelaide students were obtained as part of their dental course requirements and were selected from a larger collection. M1 and M2 were measured using a pair of sliding digital calipers to an accuracy of $0.05 \mathrm{~mm}$. The selected dimensions of the tooth crowns that were measured are shown in Figure 1.

The methods adopted to measure mesiodistal and buccolingual crown diameters were as described by Fujita (1949). Mesiodistal crown diameters of the trigonid and talonid were recorded as described by Yamada (1992), and buccolingual crown diameters of the trigonid and talonid followed the definitions given by Kondo et al. (1998). A suggestion made by Yamada (1992) was adopted to make it possible to define the border between the trigonid and talonid by defining the midpoint between the mesial central fossa and the intersection of the buccal groove.

Comparisons of mean values for mandibular molar crown dimensions between the Mongolian and

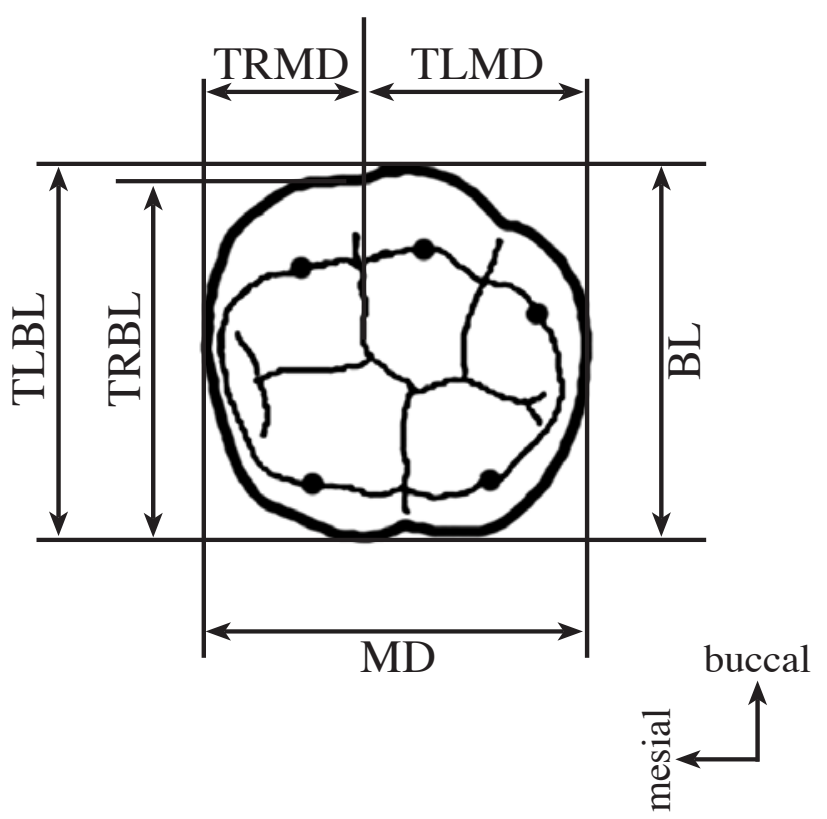

Fig. 1. Tooth crown dimensions selected for measurements. Abbreviations: BL, buccolingual diameter; MD, mesiodistal diameter; TRBL, buccolingual diameter of trigonid; TRMD, mesiodistal diameter of trigonid; TLBL, buccolingual diameter of talonid; TLMD, mesiodistal diameter of talonid.

Caucasian samples were made using Student's t-test. F-tests were used to compare variances. Statistical significance was set at alpha $=0.05$. Descriptive statistics including distribution parameters were calculated with StatView (SAS institute, version 5.0 for Macintosh).

Measurement errors were analyzed by a procedure of double determination measurements using paired t-tests (statistical significance set at alpha $=0.05$ ) for systematic errors and the method described by Dahlberg (1940) for random errors.

\section{RESULTS}

With reference to systematic errors, there were significant differences between first and second measurements for the following dimensions: in the Mongolian sample: TLMD for the right M1, TRMD for the left M1, and TLMD and TRMD for the left M2 in the Mongolian sample; MD, BL and TLBL for the right M1, MD, and TLBL for the right M2 in the Caucasian sample. However, the magnitudes of mean differences between first and second determinations were relatively small, ranging from 0.01 to $0.21 \mathrm{~mm}$. Random measurement errors ranged from 0.09 to $0.22 \mathrm{~mm}$ and these values were very small in magnitude compared with the mean values. Therefore, it was confirmed that errors of the method were relatively small and unlikely to bias results. 
TABLE 1. Descriptive statistics of crown diameters in the mandibular first molar ( $\mathrm{mm}$ )

\begin{tabular}{|c|c|c|c|c|c|c|c|c|c|}
\hline & \multicolumn{4}{|c|}{ Mongolian (female) } & \multirow[b]{2}{*}{ Significance } & \multicolumn{4}{|c|}{ Caucasian (female) } \\
\hline & $\mathrm{n}$ & mean & $\mathrm{sd}$ & CV $(\%)$ & & $\mathrm{n}$ & mean & sd & $\mathrm{CV}(\%)$ \\
\hline \multicolumn{10}{|c|}{ Right side } \\
\hline MD & 48 & 10.93 & 0.50 & 4.6 & ns & 50 & 10.69 & 0.63 & 5.9 \\
\hline TLMD & 48 & 6.23 & 0.55 & 8.8 & ns & 50 & 5.99 & 0.59 & 9.8 \\
\hline TRMD & 48 & 4.69 & 0.29 & 6.3 & ns & 50 & 4.70 & 0.35 & 7.6 \\
\hline BL & 48 & 10.51 & 0.39 & 4.3 & $* *$ & 50 & 10.25 & 0.46 & 4.5 \\
\hline TLBL & 48 & 10.43 & 0.45 & 4.4 & * & 50 & 10.16 & 0.48 & 4.7 \\
\hline TRBL & 48 & 10.31 & 0.45 & 7.5 & $* *$ & 50 & 10.05 & 0.52 & 5.2 \\
\hline \multicolumn{10}{|c|}{ Left side } \\
\hline MD & 48 & 10.96 & 0.51 & 4.6 & ns & 50 & 10.73 & 0.61 & 5.7 \\
\hline TLMD & 48 & 6.27 & 0.51 & 8.2 & ns & 50 & 6.12 & 0.61 & 10.0 \\
\hline TRMD & 48 & 4.69 & 0.38 & 8.0 & ns & 50 & 4.61 & 0.38 & 8.3 \\
\hline $\mathrm{BL}$ & 48 & 10.52 & 0.39 & 3.9 & $* *$ & 50 & 10.28 & 0.49 & 4.8 \\
\hline TLBL & 48 & 10.40 & 0.40 & 3.5 & * & 50 & 10.21 & 0.51 & 5.0 \\
\hline TRBL & 48 & 10.36 & 0.36 & 6.9 & $* *$ & 50 & 10.11 & 0.48 & 4.7 \\
\hline
\end{tabular}

ns: not significant

${ }^{*} 0.05>\mathrm{P}>0.01 ; * * \mathrm{P}<0.01$

$\mathrm{CV}=(\mathrm{sd} /$ mean $) 100$

TABLE 2. Descriptive statistics of crown diameters in the mandibular second molar ( $\mathrm{mm}$ )

\begin{tabular}{|c|c|c|c|c|c|c|c|c|c|}
\hline & \multicolumn{4}{|c|}{ Mongolian (female) } & \multirow[b]{2}{*}{ Significance } & \multicolumn{4}{|c|}{ Caucasian (female) } \\
\hline & $\mathrm{n}$ & mean & SD & $\mathrm{CV}(\%)$ & & $\mathrm{n}$ & mean & $\mathrm{SD}$ & $\mathrm{CV}(\%)$ \\
\hline \multicolumn{10}{|c|}{ Right side } \\
\hline MD & 48 & 10.12 & 0.75 & 7.4 & ns & 50 & 10.15 & 0.61 & 6.1 \\
\hline TLMD & 48 & 5.18 & 0.62 & 12.0 & ** & 50 & 4.81 & 0.48 & 10.0 \\
\hline TRMD & 48 & 4.94 & 0.38 & 7.7 & ** & 50 & 5.34 & 0.48 & 9.0 \\
\hline BL & 48 & 10.07 & 0.47 & 4.7 & * & 50 & 9.82 & 0.62 & 6.3 \\
\hline TLBL & 48 & 9.93 & 0.53 & 5.4 & ** & 50 & 9.44 & 0.60 & 6.4 \\
\hline TRBL & 48 & 9.89 & 0.54 & 5.4 & ns & 50 & 9.73 & 0.69 & 7.1 \\
\hline \multicolumn{10}{|c|}{ Left side } \\
\hline MD & 48 & 10.05 & 0.69 & 6.9 & ns & 50 & 10.11 & 0.62 & 6.2 \\
\hline TLMD & 48 & 5.12 & 0.59 & 11.6 & * & 50 & 4.89 & 0.55 & 11.3 \\
\hline TRMD & 48 & 4.93 & 0.37 & 7.5 & ** & 50 & 5.22 & 0.43 & 8.3 \\
\hline BL & 48 & 10.08 & 0.43 & 4.3 & ns & 50 & 9.94 & 0.62 & 6.3 \\
\hline TLBL & 48 & 9.92 & 0.46 & 4.6 & ** & 50 & 9.51 & 0.69 & 7.3 \\
\hline TRBL & 48 & 9.95 & 0.49 & 4.9 & ns & 50 & 9.89 & 0.64 & 6.5 \\
\hline
\end{tabular}

ns: not significant

${ }^{*} 0.05>\mathrm{P}>0.01 ; * * \mathrm{P}<0.01$

$\mathrm{CV}=(\mathrm{sd} /$ mean $) 100$ 
TABLE 3. Descriptive statistics of reduction indices (\%) for the mandibular second molar

\begin{tabular}{|c|c|c|c|c|c|c|c|c|c|}
\hline & \multicolumn{4}{|c|}{ Mongolian (female) } & \multirow[b]{2}{*}{ Significance } & \multicolumn{4}{|c|}{ Caucasian (female) } \\
\hline & $\mathrm{n}$ & mean & $\mathrm{SD}$ & CV $(\%)$ & & $\mathrm{n}$ & mean & SD & CV $(\%)$ \\
\hline \multicolumn{10}{|c|}{ Right side } \\
\hline MD & 48 & 92.61 & 4.91 & 5.3 & ** & 50 & 94.99 & 3.36 & 5.9 \\
\hline TLMD & 48 & 83.31 & 8.95 & 10.7 & ns & 50 & 80.62 & 7.62 & 9.8 \\
\hline TRMD & 48 & 105.58 & 9.04 & 8.6 & $* *$ & 50 & 113.86 & 9.32 & 7.6 \\
\hline BL & 48 & 95.77 & 3.15 & 3.3 & ns & 50 & 95.87 & 3.93 & 4.5 \\
\hline TLBL & 48 & 95.29 & 3.50 & 3.7 & $* *$ & 50 & 92.91 & 4.27 & 4.7 \\
\hline TRBL & 48 & 95.96 & 4.00 & 4.2 & ns & 50 & 96.79 & 4.52 & 5.2 \\
\hline \multicolumn{10}{|c|}{ Left side } \\
\hline MD & 48 & 91.74 & 4.68 & 5.1 & $* *$ & 50 & 94.20 & 3.94 & 4.2 \\
\hline TLMD & 48 & 81.71 & 7.04 & 8.6 & ns & 50 & 80.21 & 8.62 & 10.8 \\
\hline TRMD & 48 & 105.56 & 8.00 & 7.6 & $* *$ & 50 & 113.59 & 10.33 & 9.1 \\
\hline BL & 48 & 95.85 & 2.76 & 2.9 & ns & 50 & 96.72 & 3.48 & 3.6 \\
\hline TLBL & 48 & 95.37 & 2.88 & 3.0 & $* *$ & 50 & 93.09 & 4.34 & 4.7 \\
\hline TRBL & 48 & 96.02 & 3.30 & 3.4 & $* *$ & 50 & 97.76 & 3.43 & 3.5 \\
\hline
\end{tabular}

ns: not significant

${ }^{*} 0.05>\mathrm{P}>0.01 ; * * \mathrm{P}<0.01$

$\mathrm{CV}=(\mathrm{sd} /$ mean $) 100$

Comparisons between right and left side measurements of M1 and M2 were made using paired t-tests (statistical significance set at alpha $=0.05$ ). In the Mongolian sample, there was no significant difference between sides but, in the Caucasian sample, there were significant differences between right and left sides, namely for TLMD and TRMD of M1, and TRMD, BL and TRBL of M2. The magnitude of differences ranged from 0.03 to $0.12 \mathrm{~mm}$.

Table 1 shows basic descriptive statistics of crown diameters in the Mongolian and Caucasian samples for M1. When consideration was given to mesiodistal crown diameters, there was no significant difference between Mongolian and Caucasian samples on either right or left sides. However, all the buccolingual crown diameters of the Mongolian sample were significantly larger than those of Caucasians; that is, BL, TLBL and TRBL were all larger. Coefficients of variation showed that TLMD, TRMD and TRBL displayed the greatest variation in the Mongolian sample, and TLMD and TRMD also displayed high relative variability in the Caucasian sample.

Table 2 shows basic descriptive statistics of crown diameters in Mongolian and Caucasian samples for M2. Two dimensions displayed statistically significant differences between the samples: TLMD was significantly larger in Mongolians than in Caucasians, whereas TRMD was significantly smaller in Mongolians than in Caucasians. However, there was no significant difference between Mongolian and Caucasian samples in MD dimensions. With reference to the buccolingual crown diameters, there was a significant difference only for BL on the right side between the Mongolian and Caucasian samples. TLBL in Mongolians was significantly larger than those of the Caucasians but there was no statistically significant difference between the samples for TRBL. Coefficients of variation showed that MD, TLMD and TRMD displayed high relative variation in Mongolians and TLMD, TRMD also displayed high coefficients of variation in Caucasians.

Table 3 shows basic descriptive statistics of reduction indices of crown measurements for M2 compared with M1 in the Mongolian and Caucasian samples. For reduction indices of mesiodistal crown dimensions, there were two significant differences between Mongolian and Caucasian samples, namely MD and TRMD. Both were significantly smaller in Mongolians compared with Caucasians but the reduction index of MD was less than 100 whereas that for TRMD was over 100-indicating a reduction for MD but an enlargement for TRMD of $\mathrm{M} 2$ relative to M1. The values of reduction indices for TLMD were the lowest of all variables, indicating that the largest reduction in size from M1 to M2 occurred in TLMD in both Mongolian and Caucasian samples. For buccolingual crown dimensions, there was no significant difference in the mean value of reduction indices for BL between Mongolian and Caucasian samples. However, there was a significant difference in the mean reduction index of TLBL between samples, with the mean value being lower in Caucasians. There was also a significant 
difference for reduction indices of TRBL on the left side only between Mongolian and Caucasian samples.

\section{DISCUSSION}

The lower first molar begins to form around 30 weeks in utero and crowns have completed their formation at approximately three years after birth. In contrast, lower second molars commence to form around three years after birth and their crowns are fully-formed by approximately seven years (Christensen and Kraus, 1965; Oka and Kraus, 1969). Most permanent lower molars have five cusps: mesiobuccal, mesiolingual, distobuccal, distolingual, and distal. During formation the mesiobuccal cusp is always the first to start development, followed by mesiolingual, distobuccal, and then the distolingual. The last component of the crown to form is the distal cusp (Christensen and Kraus, 1965; Hillson, 1996). The trigonid consists of the mesiobuccal and mesiolingual cusps, while the talonid consists of the distobuccal, distolingual and distal cusps. In four-cusped molars, the distal cusp is missing.

Our study has shown that BL, TLBL and TRBL dimensions in M1 of the Mongolian sample were significantly larger than those of the Caucasian sample. In contrast, there was no significant difference in the MD, TLMD and TRMD dimensions. Thus, there was a significant size difference in buccolingual dimensions but not in mesiodistal dimensions between the two samples.

Tooth size variability appears to have a strong genetic component, but environmental factors are also of importance (Dempsey and Townsend, 2001). Indeed, there is evidence that common environmental contributions to tooth size variability are greater for buccolingual dimensions than mesiodistal ones (Townsend and Brown, 1978). The buccolingual diameters of both the talonid (distal part of the crown) and trigonid (mesial part of the crown) of M1 in Mongolians were significantly larger than in Caucasians. This suggests that common environmental effects, possibly related to the prenatal environment, as well as genetic influences, may be contributing to the differences in buccolingual dimensions between Mongolians and Caucasians.

For M2, there were significant differences between Mongolians and Caucasians for TLMD, TRMD, right BL and TLBL. The mean values for TLMD, TRMD and TLBL differed by around 5\% whereas the difference in the means for BL (right side only) between Mongolians and Caucasians was around only $2 \%$. The diameters of the talonid (TLMD and TLBL) of Mongolians were significantly larger than those of Caucasians. On the other hand, TRMD in Mongolians was significantly smaller than in Caucasians. Furthermore, there was no significant difference in TRBL. Thus, the mesiodistal and buccolingual diameters of the distal part of tooth crown in the Mongolian sample were significantly larger and the mesiodistal and buccolingual diameters of mesial part were significantly smaller compared with those of Caucasians. It is difficult to explain why this differential effect exists. It may be due to an interaction between these two crown components during development, with larger earlier-forming components being associated with smaller later-developing components. Alternatively, the finding could be due to chance variation associated with a small sample size.

The last tooth to develop in each class tends to be the most variable in size and shape (Dahlberg, 1945). This variability is thought to be due to greater environmental influence during development linked to a decrease in intrinsic genetic control over tooth size from the early to the late developing teeth within each class (Sofaer et al., 1971). Given that the M2 develops later and over a longer period of time than the M1, it is reasonable to assume that this tooth may be subject to greater environmental pressures than would be applied to the M1. Indeed, the dimensions of M2 tended to display more variation, as evidenced by the values of CVs, than those of M1. The M2 develops later than the M1, therefore, environmental influences acting an each population may have contributed more to size variation than genetic factors for M2 compared with M1.

The reduction indices of $\mathrm{MD}$ and TRMD were significantly smaller in the Mongolian sample compared with Caucasians. This indicates that overall mesiodistal crown size of M2 in Mongolians, and also the mesiodistal size of the trigonid, are more reduced compared to M1. In contrast, the reduction indices for TRMD did not differ significantly between the samples. The reduction index for TLBL was larger in Mongolians, confirming that this dimension did not reduce as much in M2 compared with M1 as it did in Caucasians. Our results are consistent with the findings of Kondo et al. (2005) and show a tendency for increasing size in the mesial component of molar crowns and decreasing size in the distal component when comparing M2 to M1. They are also consistent with the findings of Yamada (1992) who noted that the distal part of molars was most affected by morphological variations, including tooth size reduction.

In the maxillary molars, the mesiobuccal cusp generally increases in size from M1 to M2 and reduces from M2 to M3. The mesiolingual cusp follows a pattern similar to that of the mesiobuccal, whereas the distobuccal cusp shows a marked reduction in size from M1 to M3 (Macho and Moggi-Cecchi, 1992). It would seem that there are also interactions between the mesial and distal crown components of maxillary molars as well as mandibular ones. The mesial crown component may tend to become larger to maintain the occlusal surface area of M2 as the distal component is reduced. A broader occlusal surface is likely to be advantageous for masticatory activity (e.g., crushing and/or grinding food), and the enlargement of mesial crown component makes the occlusal surface broader as overall tooth size 
is reduced. Overall molar crown size and intra-coronal components showed differential patterns of reduction in the two study samples, as has been shown between other living human populations (Kanazawa et al., 1985; Kondo et al., 2005).

This study has investigated the size relationships between the talonid and trigonid of M1 and M2 in Mongolian and Caucasian samples. Sexual dimorphism was not explored in this study but it is planned to collect data from male Mongolians in the future. Once we have gained greater knowledge of tooth size variation in Mongolians, it will be of interest to compare tooth size in Mongolians with Japanese, bearing in mind that both groups share a Sinodont dental pattern.

\section{ACKNOWLEDGEMENTS}

Wearegratefulfor theassistance of AssociateProfessor Shintaro Kondo who made valuable suggestions regarding study methods. We are also indebted to the staff of the Schools of Dentistry of both the Health Science University of Mongolia and the University of Adelaide. The dental casts of Mongolians used in this study were collected during a dental anthropological survey in 2006. The dental casts of Caucasians used in this study were collected from the students of the School of Dentistry, the University of Adelaide, from 1982 to 1991.

\section{LITERATURE CITED}

Chimge N, Batsuuri J. 1999. Interethnic genetic differentiation: HLA Class I antigens in the population of Mongolia. Am J Hum Biol 11:603-618.

Christensen GJ, Kraus BS. 1965. Initial calcification of the human permanent first molar. J Dent Res 44:13381342.

Dahlberg AA. 1945. The changing dentition of man. J Am Dent Assoc 32:676-690.

Dahlberg G. 1940. Statistical methods for medical and biological students. London: George Allen and Unwin Ltd.

Dempsey PJ, Townsend GC. 2001. Genetic and environmental contributions to variation in human tooth size. Heredity 86:685-693.

Fujita T. 1949. On the standard of the measurement of teeth. J Anthropol Soc Nippon 61:27-32 (In Japanese with German summary).

Goyal HD. 1999. A development perspective on Mongolia. Asian Survey 39:633-655.

Hanihara T, Ishida H. 2005. Metric dental variation of major human populations. Am J Phys Anthropol 128:287-298.

Hillson S. 1996. Dental anthropology. Cambridge, England: Cambridge University Press.

Kanazawa E, Sekikawa M, Akai J, Ozaki T. 1985. Allometric variation on cuspal areas of the lower first molar in three racial populations. J Anthropol
Soc Nippon 93:425-438.

Kondo S, Funatsu T, Amino S, Sasa R, Wakatsuki E. 1998. An odontometrical analysis of the mandibular molariform teeth in the Japanese males. Pediatr Dent J 8:73-77

Kondo S, Townsend GC, Nakajima K, Yamada H, Wakatsuki E. 1999. Size of crown components of the mandibular deciduous and permanent molars in Australian Aborigines. In: Mayhall JT, Heikkinen T, editors. Dental morphology 1998. Oulu, Finland: Oulu University Press. p 150-156.

Kondo S, Townsend GC, Kanazawa E. 2005. Size relationships among permanent mandibular molars in Aboriginal Australians and Papua New Guinea Highlanders. Am J Hum Biol 17:622-633.

Macho GA, Moggi-Cecchi J. 1992. Reduction of maxillary molars in Homo sapiens sapiens: a different pespective. Am J Phys Anthropol 87:151-159.

Manabe Y, Oyamada J, Kitagawa Y, Rokutanda A, Kato K, Matsushita T. 2003. Dental morphology of the Dawenkou Neolithic population in North China: implications for the origin and distribution of Sinodonty. J Hum Evol 45:369-380.

Matsumura H. 1995. Dental characteristics affinities of the prehistoric to the modern Japanese with the East Asians, American Natives and Australo-Melanesians. Anthropol Sci 103:235-261.

Matsumura H, Hudson MJ. 2005. Dental perspectives on the population history of Southeast Asia. Am J Phys Anthropol 127:182-209.

Oka SW, Kraus BS. 1969. The circumnatal status of molar crown maturation among the Hominoidea. Arch Oral Biol 14:639-659.

Scott GR, Turner CG II. 1988. Dental anthropology. Ann Rev Anthropol 17:99-126.

Sofaer JA, Bailit HL, MacLean CJ. 1971. A developmental basis for differential tooth reduction during hominid evolution. Evolution 25:509-517.

Sofaer JA. 1973. A model relating developmental interaction and differential evolutionary reduction of tooth size. Evolution 27:427-434.

Townsend GC, Brown T. 1978. Heritability of permanent tooth size. Am J Phys Anthropol 49:497-504.

Turner CG II. 1990. Major features of Sundadonty and Sinodonty, including suggestions about east Asian microevolution, population history, and late Pleistocene relationships with Australian Aboriginals. Am J Phys Anthropol 82:295-317.

Van Valen L. 1962. Growth field in the dentition of Peromyscos. Evolution 16:272-277.

Yamada H. 1992. On the "talonid" in Japanese lower molars. Jpn J Oral Biol 34:15-24 (In Japanese with English summary). 